\title{
Neural model of biological motion recognition based on shading cues
}

\author{
Leonid A Fedorov ${ }^{*}$, Martin A Giese \\ From 24th Annual Computational Neuroscience Meeting: CNS*2015 \\ Prague, Czech Republic. 18-23 July 2015
}

Point-light or stick-figure biological motion stimuli, due to the absence of depth cues, can induce bistable perception, where the walker is perceived as heading in two alternating directions [1,2]. Psychophysical studies suggested an importance of depth cues for biological motion perception [3]. However, neural models of biological motion perception so far have focused on the processing of features that characterize the 2D structure and motion of the human body $[4,5]$. We extend such models for the processing of shading cues in order to analyze the three-dimensional structure of walkers from monocular stimuli.

\section{Model}

As extension of a learning-based neural model [4], we add a 'shading pathway' that computes the internal contrast gradients that vary with the $3 \mathrm{D}$ view of the walker, even if the silhouette information remains identical (Figure 1A-C). The model exploits physiologically plausible operations. After suppression of strong external luminance gradients caused by the boundaries of the silhouette, internal luminance gradient features are extracted by a hierarchy of neural detectors. These gradient features, combined with the shape features extracted by the form pathway of the model in [4], are used as input for 'snapshot neurons', RBF units that detect 3D body shapes (Figure 1D). These model neurons are embedded within a two-dimensional recurrent neural field [6] that jointly represents the sequential temporal structure of the stimulus and the view of the walker.

\section{Results}

The neural field dynamics reproduces perceptual multistability and spontaneous perceptual switching between

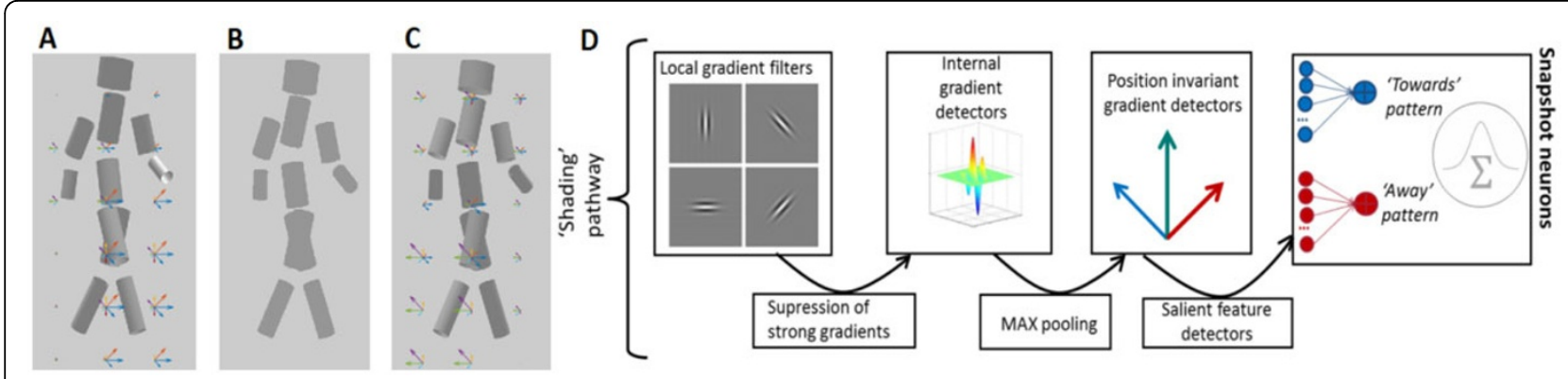

Figure $1 \mathrm{~A}$. Snapshot from a walker stimulus, rendered from a $\mathbf{- 4 5 ^ { \circ }}$ side view. Vectors indicate internal luminance gradients, extracted by the internal gradient detectors of the model. B. Silhouette stimulus without shading cues is ambiguous and compatible with view angles $\pm 45^{\circ}$. C. Snapshot and internal shading gradients for $+45^{\circ}$ side view. D. 'Shading pathway'. After suppression of strong boundary gradients, internal luminance gradients are extracted, using a hierarchy of neural detectors similar to a convolutional network. At the highest level is formed by 'snapshot neurons', RBF units that have been trained with keyframes from 3D walker movies, which are embedded in a dynamic neural field.

\footnotetext{
* Correspondence: leonid.fedorov@cin.uni-tuebingen.de; martin.giese@unituebingen.de

Section f. Computational Sensomotorics, Dept. of Cogn. Neurology, CIN/ HIH, University Clinic Tuebingen, Tuebingen, Germany
} 
stimulus views, observed for silhouette stimuli in psychophysical experiments $[1,2]$. It also reproduces the disambiguation by addition of shading information and a new perceptual illusion, which illustrates a lightingfrom-above prior in the processing of biological motion stimuli.

\section{Acknowledgements}

Supported by EC FP7 ABC PITN-GA-011-290011, HBP FP7-604102, Koroibot FP7-611909, COGIMON H2020-644727, DFG GI 305/4-1, DFG GZ: KA 1258/151, and BMBF, FKZ: 01GQ1002A.

Published: 18 December 2015

\section{References}

1. Vanrie J, Dekeyser M, Verfaillie K: Bistability and biasing effects in the perception of ambiguous point-light walkers. Perception 2004, 33:547-560.

2. Vangeneugden J, De Mazière P, Van Hulle M, Jaeggli T, Van Gool L Vogels R: Distinct mechanisms for coding of visual actions in macaque temporal cortex. J Neurosci 2011, 31(2):385-401.

3. Vanrie J, Verfaillie K: Perceiving depth in point-light actions. Perc Psychophys 2006, 68(4):601-612.

4. Giese MA, Poggio T: Neural mechanisms for the recognition of biological movements and action. Nat Rev Neurosci 2003, 4:179-192.

5. Lange J, Lappe M: A model of biological motion perception from configural form cues. J Neurosci 2006, 26:2894-2906.

6. Amari S: Dynamics of pattern formation in lateral inhibition type neural fields. Biol Cyb 1977, 27:77-87.

doi:10.1186/1471-2202-16-S1-P81

Cite this article as: Fedorov and Giese: Neural model of biological motion recognition based on shading cues. BMC Neuroscience 2015 16(Suppl 1):P81.

\section{Submit your next manuscript to BioMed Central} and take full advantage of:

- Convenient online submission

- Thorough peer review

- No space constraints or color figure charges

- Immediate publication on acceptance

- Inclusion in PubMed, CAS, Scopus and Google Scholar

- Research which is freely available for redistribution

Submit your manuscript at www.biomedcentral.com/submit
Ciomed Central 